\title{
ARAB GARDEN AND THE IMPACT OF THEIR CHARACTERISTICS ADAPTABILITY TO CONTEMPORARY REQUIREMENTS
}

(Received Journey 5, 2011 Accepted April 30, 2011)

The paper discusses the problem of the absence thought to Heritage and Contemporary Concept in the design of gardens and open spaces in the modern era. Which calls to make several attempts, to gardens and open spaces development. according to conditions and requirements in the modern age. The garden in Arab area not just filling the spaces of urban communities. but also has its origins and types of design, concepts and elements that represantan especial of open spaces. The paper aims at excluding characteristics of The garden in Arab area which have different forms of gardens, and analyez the requirement of open spaces in the modern era, and ensore sotability to their circumstances and possibilitie.

The paper studies the following topics

1. The introduction: it introduces the research problems, the aim, and methodology followed in the study.

2. Characteristics studys of Arab garden (Elements - designs concepts).

3. The paper which Knowing activities and contemporary requirement of open spaces and make analytical study of contemporary open spaces to stand on how to achieve the of heritage and contemporary

The research presents recommendations that aims to keep the heritage in open spaces according to the circumstances and possibilities

\section{الحديقة العربية ومدى مواكبة خصائصها للمتطلبات العصرية}
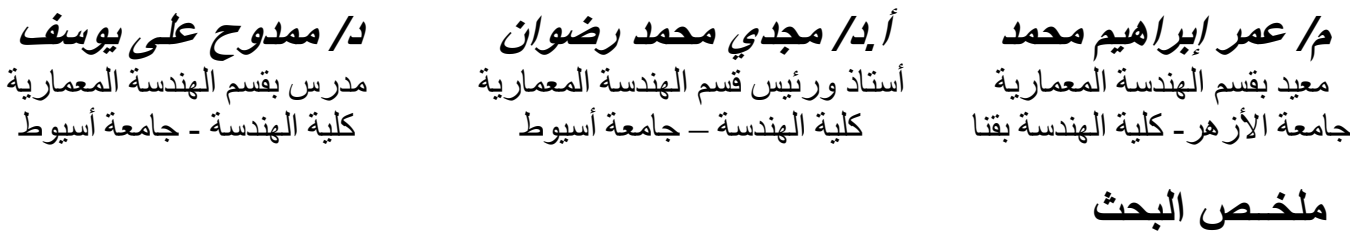

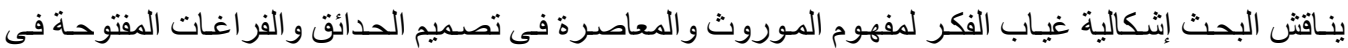

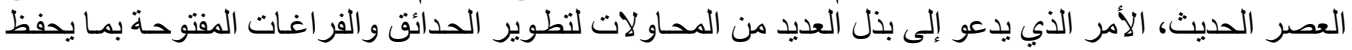

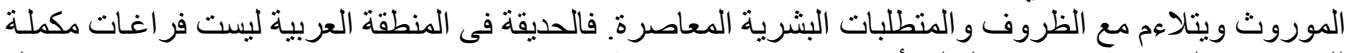

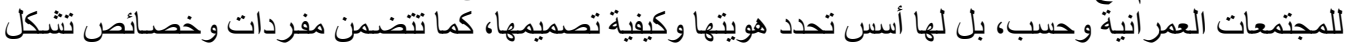

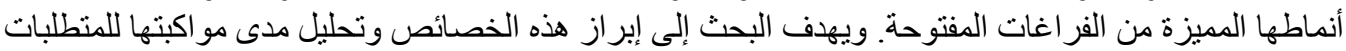

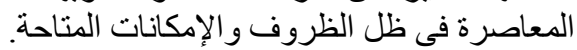

تنتاول الدر اسة النقاط التالية:

1 ) المقدمة وتضم الإشكالية و الهدف والية والمنهجية المتبعة فى الدراسة.

2) در اسة خصائص الحديقة التراثية فى المنطقة العربية ( المفردات ـ التشكيل ـ المفاهيم ) و أنماطها . 


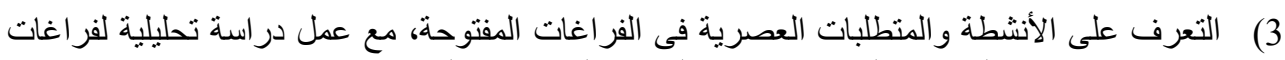

مفتوحة معاصرة و الوقوف على مدى تحقيقها لمفهوم الموروث و المعات المعاصرة.

ينتهي البحث بتوصيات توضح سبل المحافظة على الموروث وتحقيق المنطلبات المعاصرة بالفر اغات المفتوحة فى ظل الظروف و الإمكانات المناحة.

\section{1. المقدمة وتضم الإثكالية والهلف والمنهجية المتبعة في الدراسة.}

إثكالية الدراسة

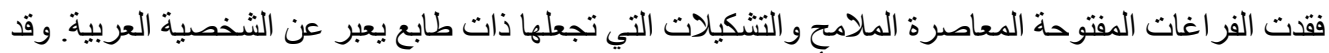

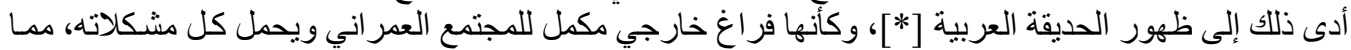

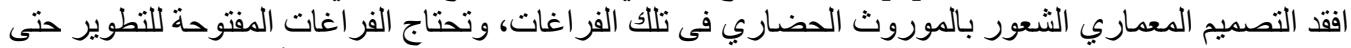

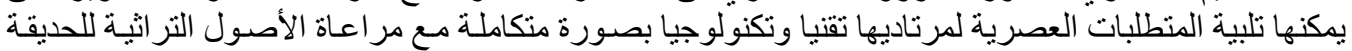

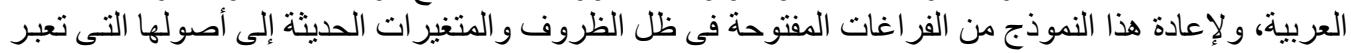

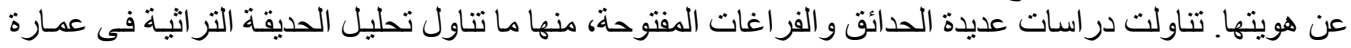

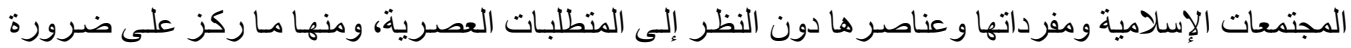

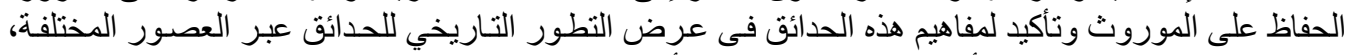

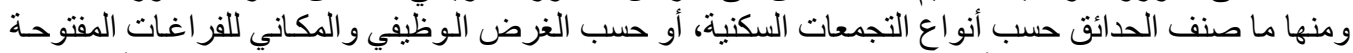

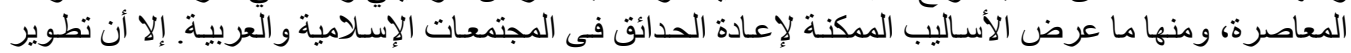

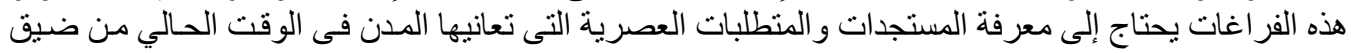

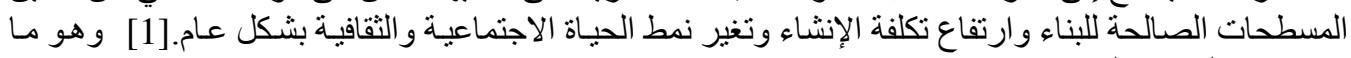
سيتعرض إليه هذا البحث.

2-1 مدف البحث

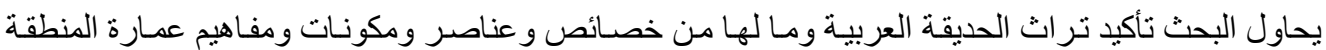

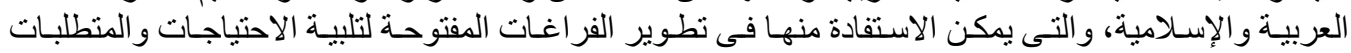

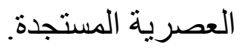

ـ ـ التعرف على تراث الحديقة العربية وإبراز الخصائص النمطية وغير النمطية من عناصر ومكونات

$$
\text { ويمكن تفصيل الهدف إلى الأتي: }
$$

وتتشكيل النمط المعماري المميز للثخصية العربية.

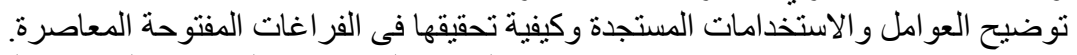

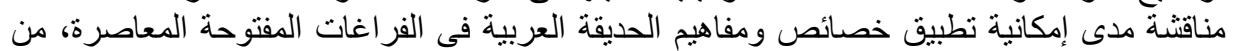

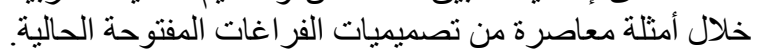

- وضع النتائج و التوصيات التى يمكن تطبيقها فى تصميم الفراغات المفتوحة المعاصرة لتلبية الاحتياجات

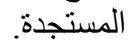

3-1

استخدم البحث المنهج النظري الوصفي لدر اسة خصائص ومكونات الحديقة التر اثية، كما يستخدم البحث المنهج التحليلي من خلال تحليل حدائق معاصرة لاستنباط المشكلات وكيفية معالجتها.

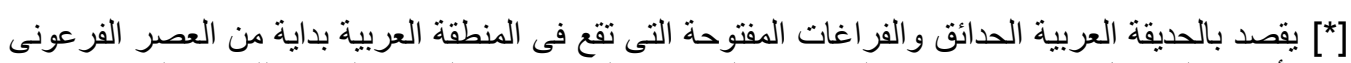

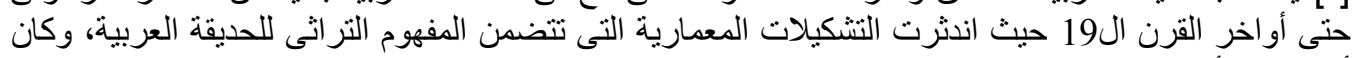




\section{2. خصائص الحديقة العربية ( المفردات - التثكيل - المفاهيم )}

أنتئت الحدائق العربية كجنات يلمح فيها مفاهيم فردوسية تعكس المردود الثقافي من جنات الخلد التي وصفها الله

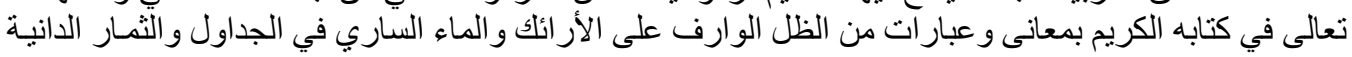

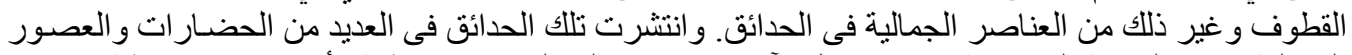

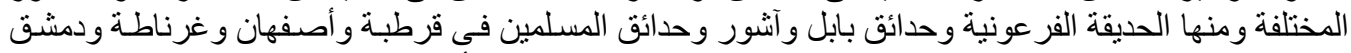

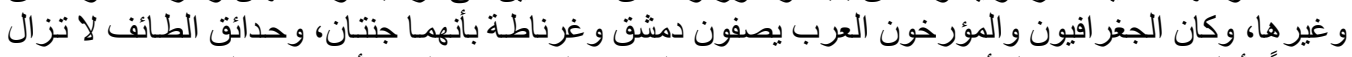

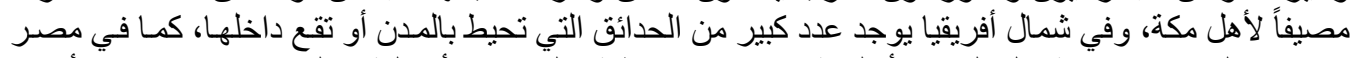

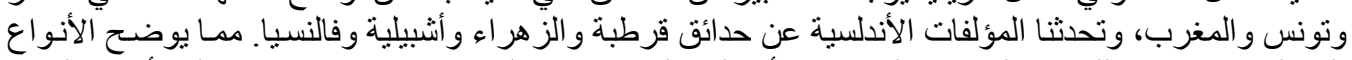

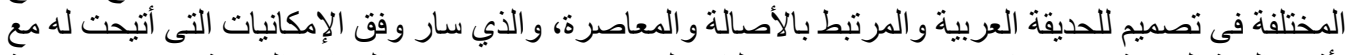

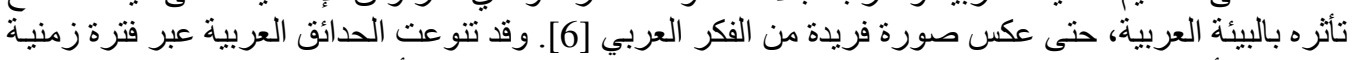

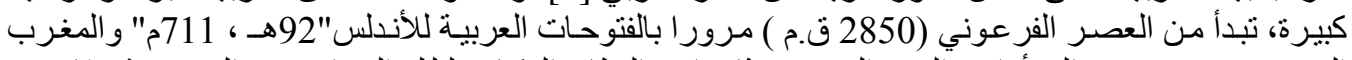

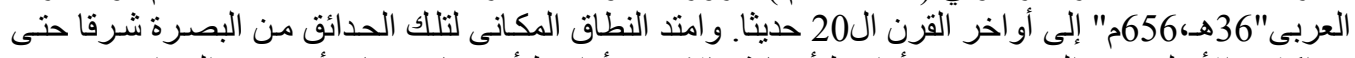

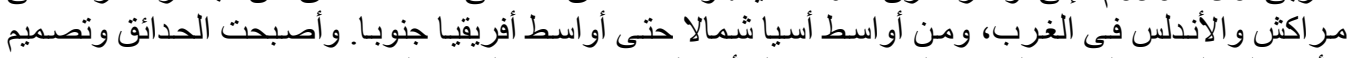

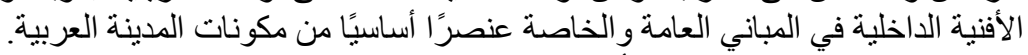

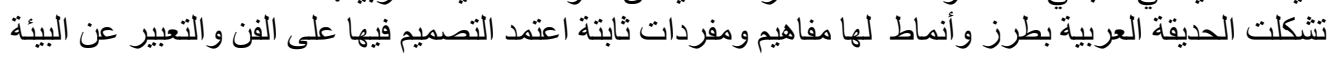

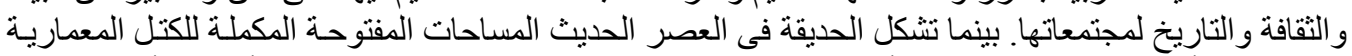

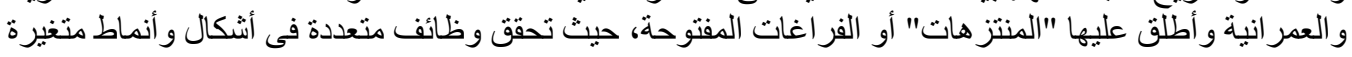

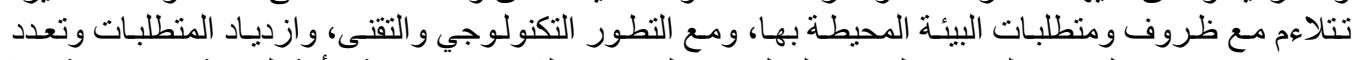

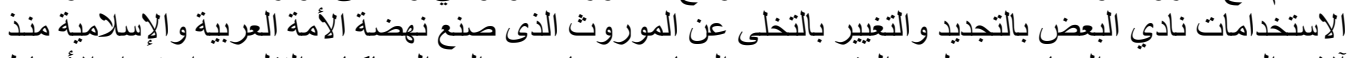

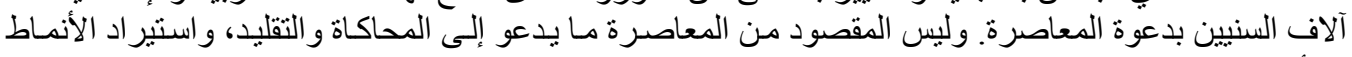

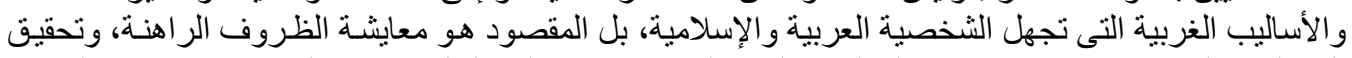

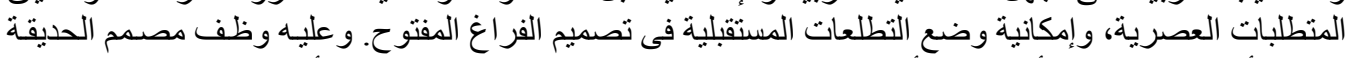

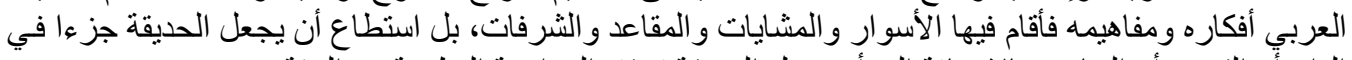

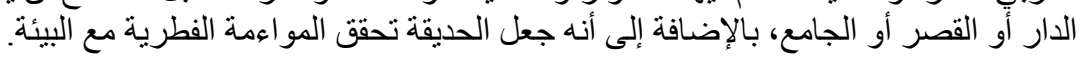

\section{1-2}

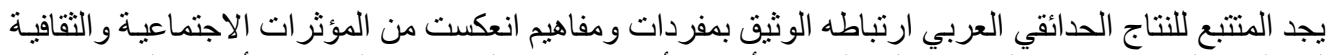

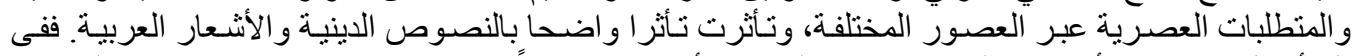

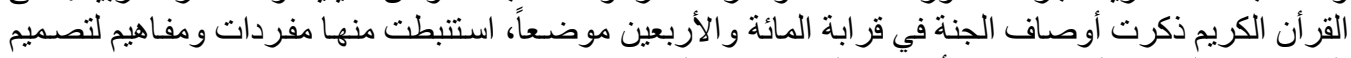

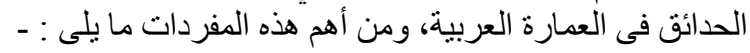

- - حتمية وجود العنصر المائي في القناء أو الحديقة: حيث ظهر تصوير الماء فى أحواض رباعية

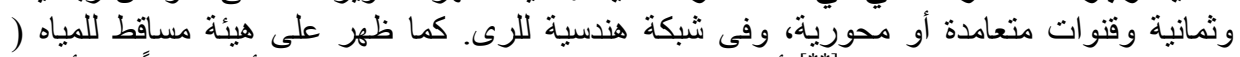

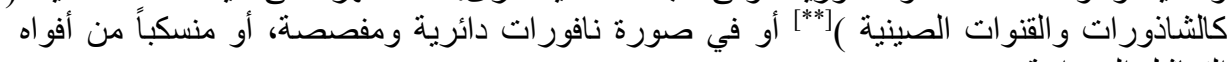

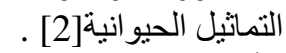

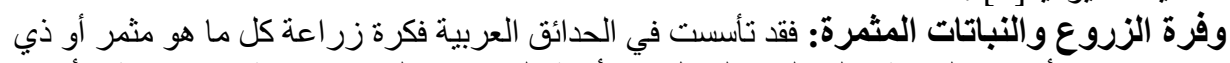

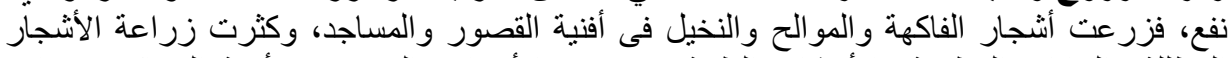

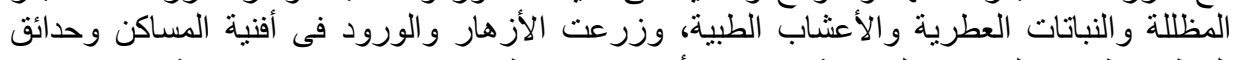

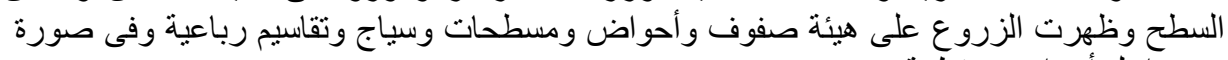

حرة داخل أحواض منتظمة.

[ [الثاذورات هي أسطح رخامية أو حجرية مائلة بها نتوءات تسبب نكون الرزاز عند تدفق الماء على سطحها فترطب الجو. .بينما

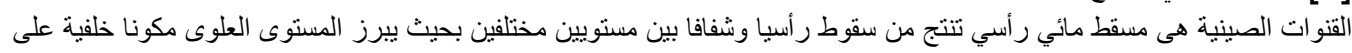




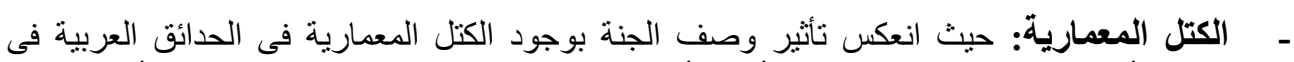

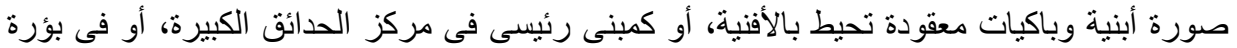

التكوين وذروته في الحدائق المتدرجة.

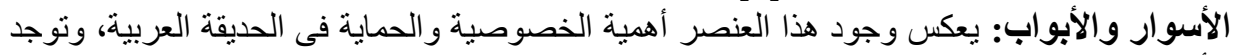

الأسوار بالحديقة العربية عالية يقطع استمر ار ها بوابات المداخل و المنار ات الركنة الرنية الخاصة بالمر اقبة.

[7]

- اصية الإظلال: تنعكس خاصية الإظلال فى الأفنية العربية نتيجة لنسب الفناء الداخلى حيث يزيد

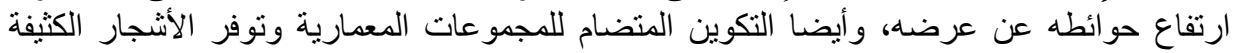

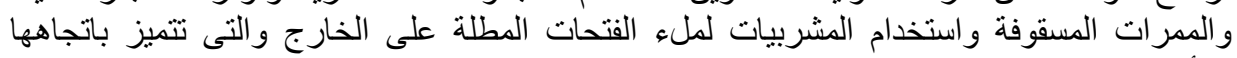

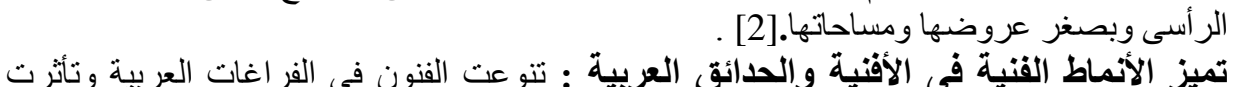
تالثقافة العربية [6]. ألماط القية فى الأقنية والحدائق العربية : تتوعت الفنون فى الفراغات العربية ونأثرت

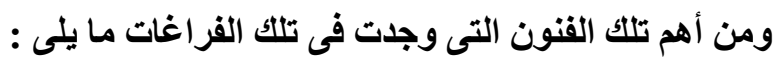

- - الأشرطة المكتوبة: منها الأشرطة القر آنية والأبيات الثعرية.

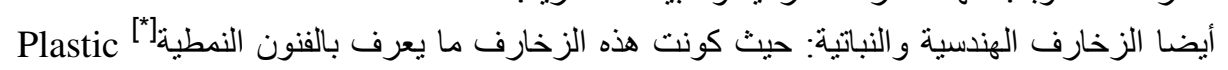

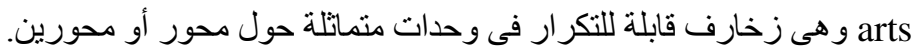
- أخير ا: ندرة الفنون التصويرية وتجريد صورتها الحية: فتميزت فنون الأفنية العربية بقلة تو اجد التماثيل

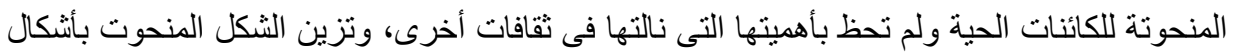

$$
\text { نباتية و هندسية. }
$$

\section{أتثكيل التصميمى للحديقة العربية}

اشتركت أنواع الحدائق العربية فى كونها مجمو عة من الأفنية الداخلية التى تحبط بها الكتلة البنانية إحاطـة كلية

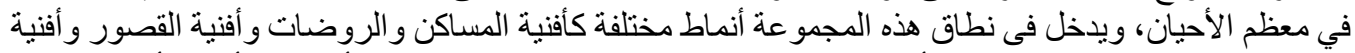

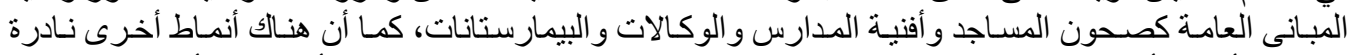

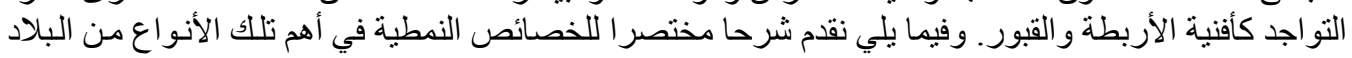
العربية [7] مأجنة

\section{أ. أفنية المساكن}

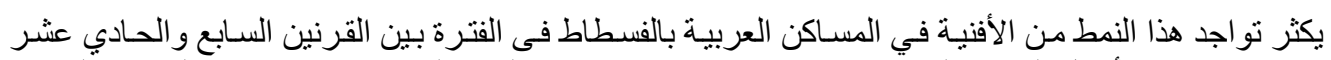

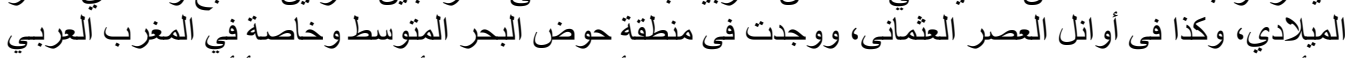

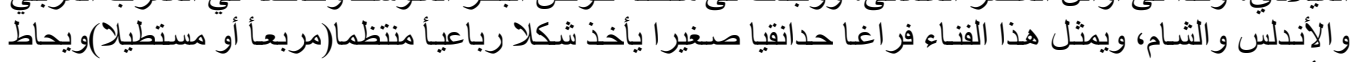

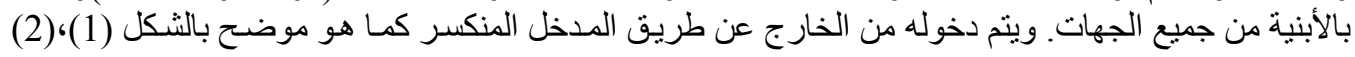

["]يقصد بمصطلح "Plastic arts" الفنون الزخرفية القابلة للتكرار والتصنيع بقوالب كالأعمال الجبسية

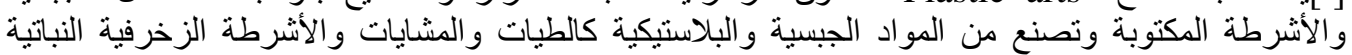
و الهندسية والمكتوبة في العصنور وتصن من التراثية. 


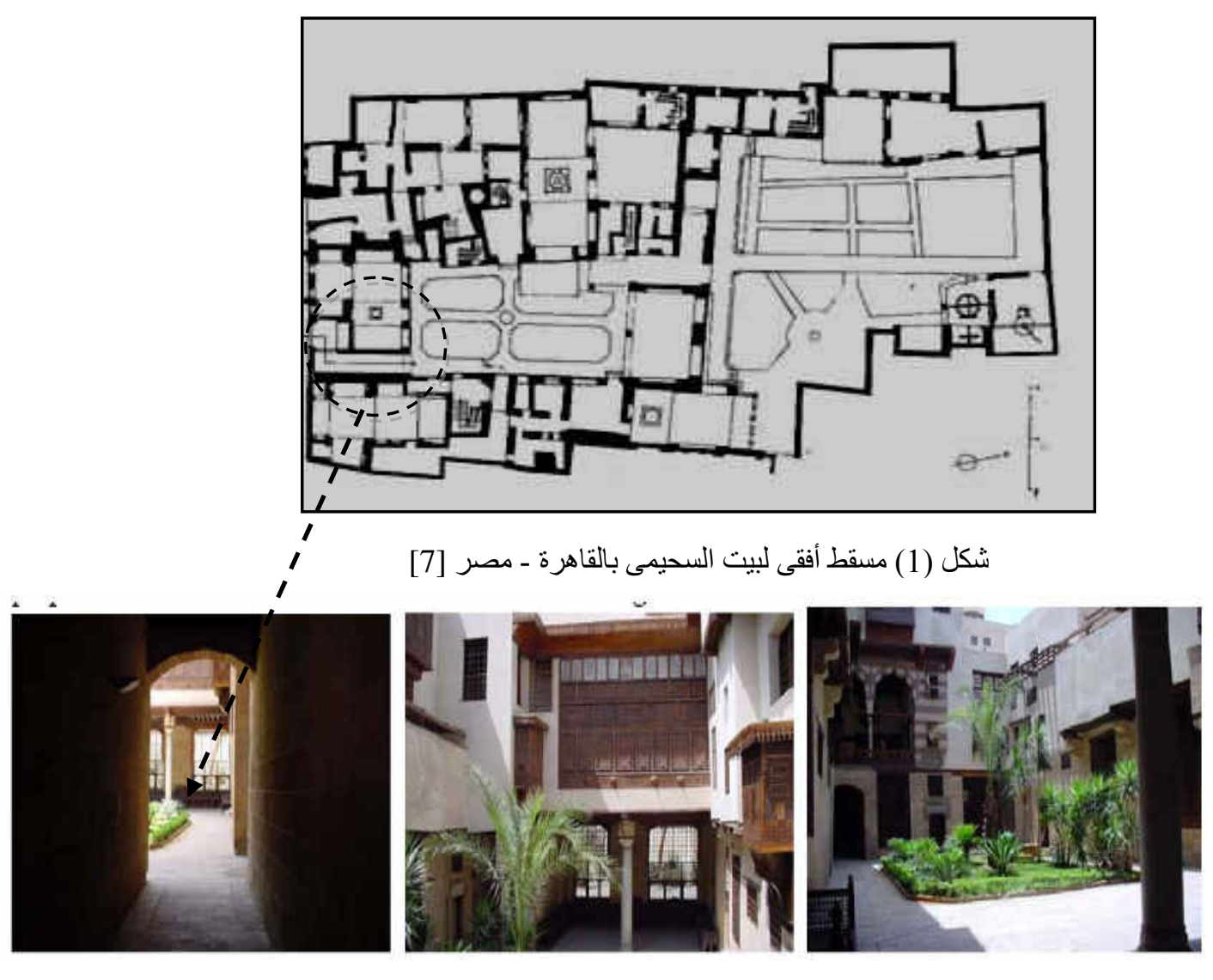

شكل (2) صور داخلية لبيت السحيمى بالقاهرة - مصر[12]

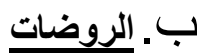

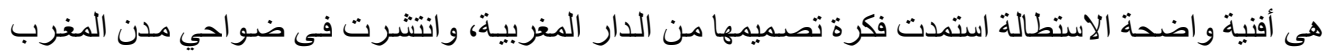

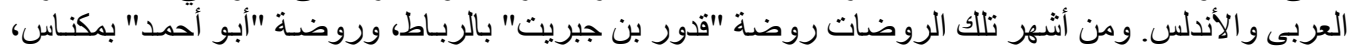

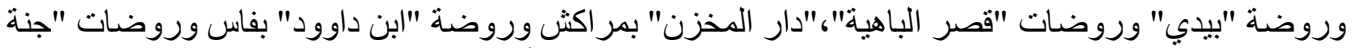

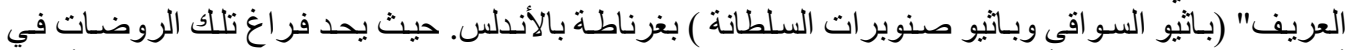

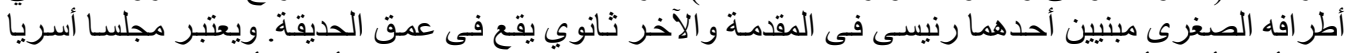

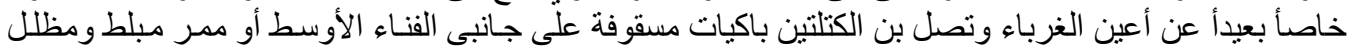

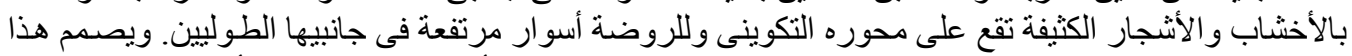

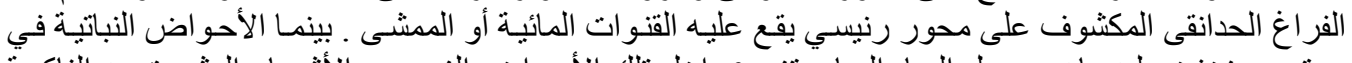

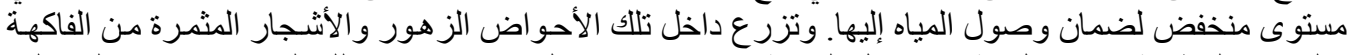

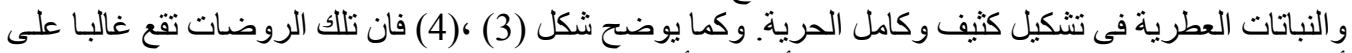

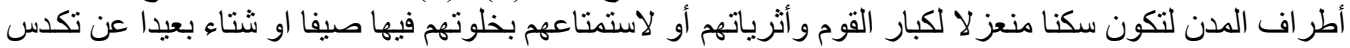

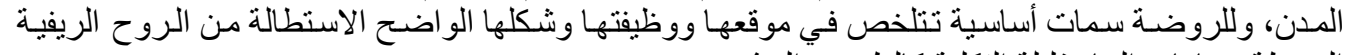

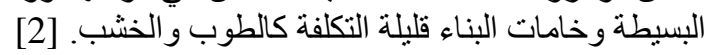




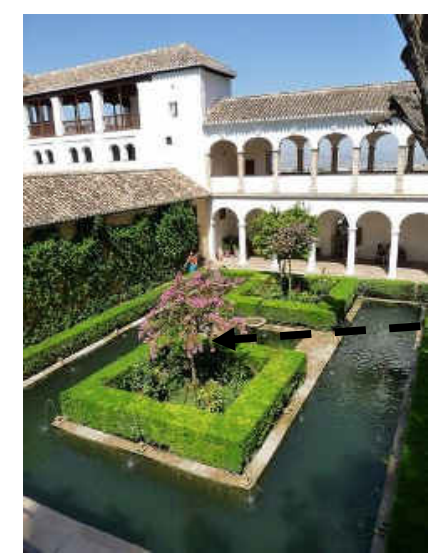

شكل ( 4 أحد روضات جنة العريف [12]- بالأندلس

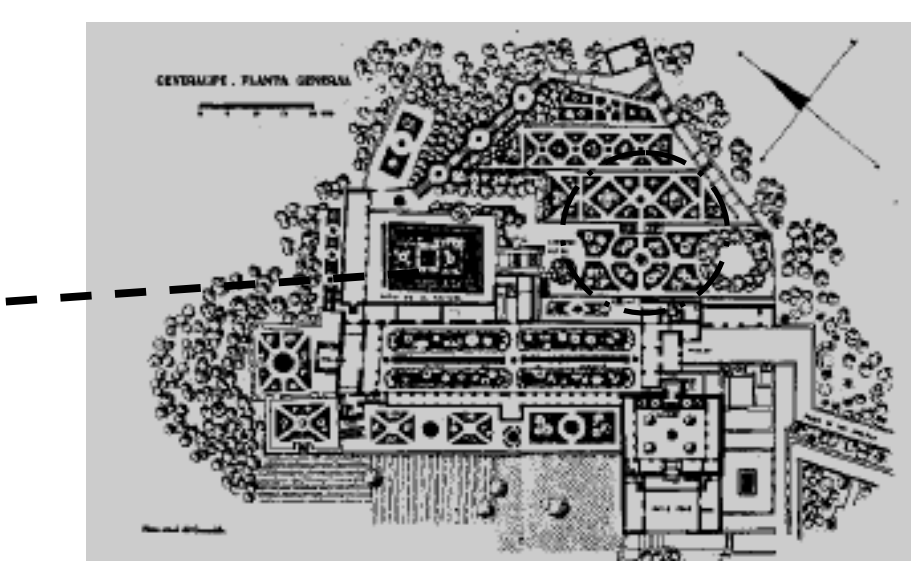

شكل (3) المسقط الافقى لروضات جنة العريف (الأندلس) [7]

\section{ج. أفنية القصور}

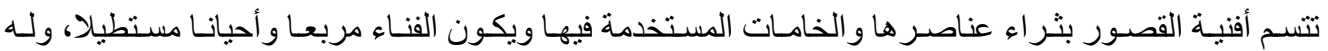

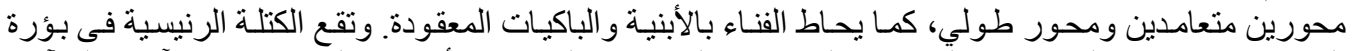

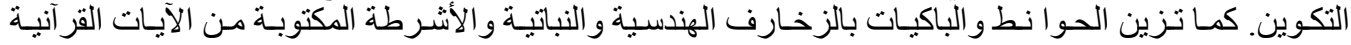

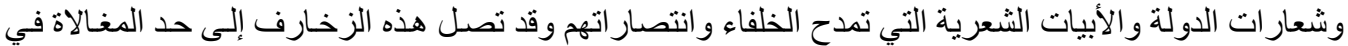

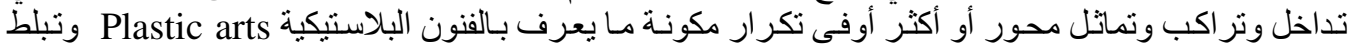

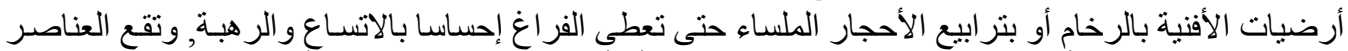

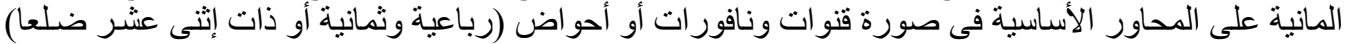

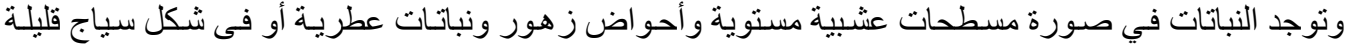

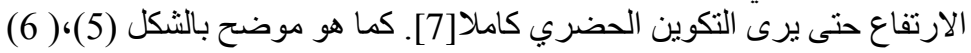

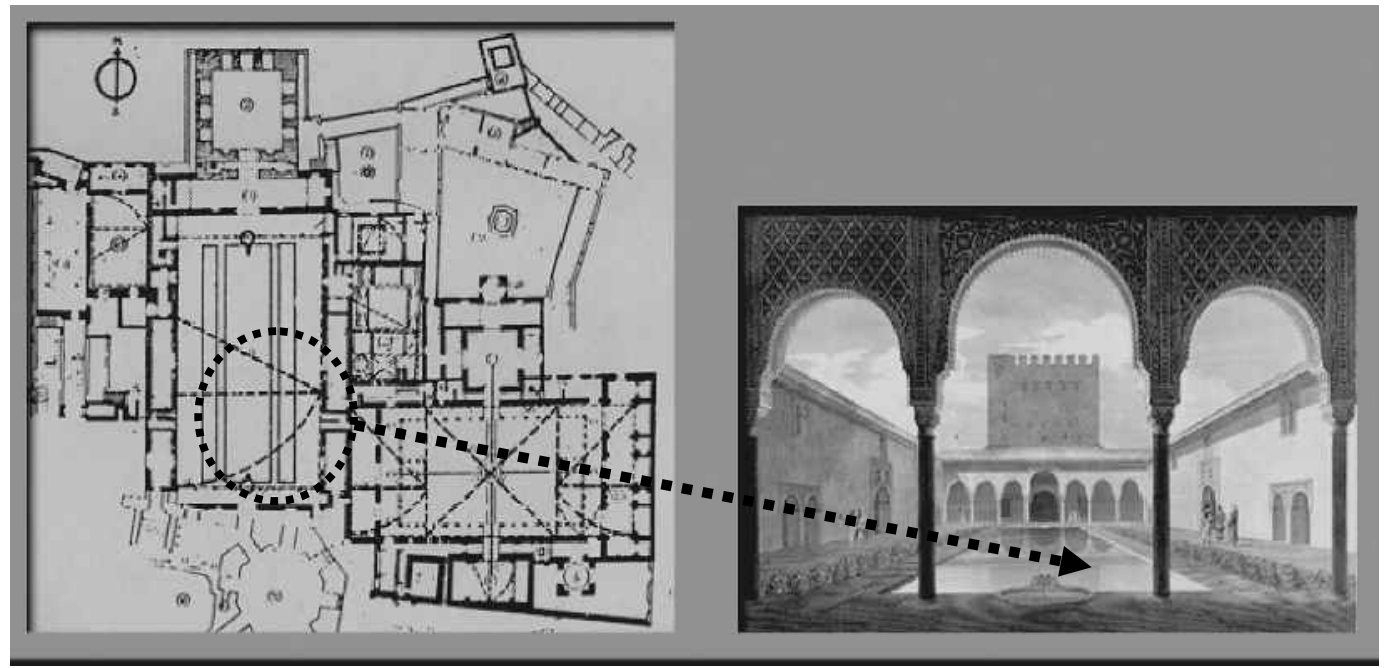

شكل ( 5) فناء الريحان من الداخل بالأندلس [3] شكل (6) المسقط الافقى لقصر الحمر اء ـ الأندلس[8] 
د. أفنية المساجد

يسمى الفر اغ المكثوف بالمسجد على وجه العموم بالصحن ويقع خلف صـالة الصـلاة الرئيسية، ويمثل امتدادا

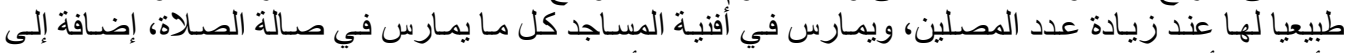

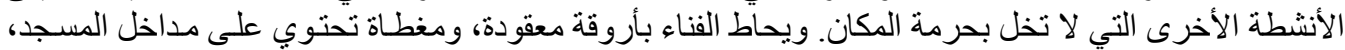

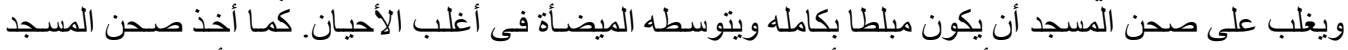

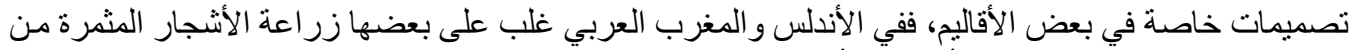

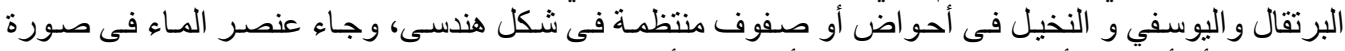

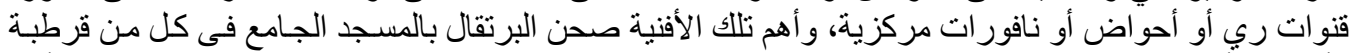

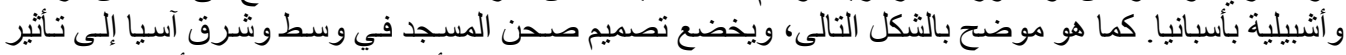

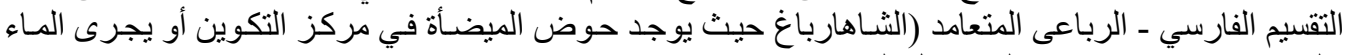

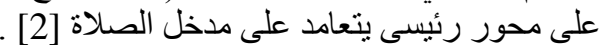

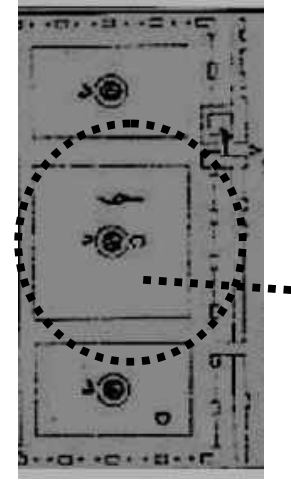

شكل (8) مسقط افقى لصحن البرتقال

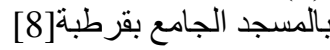

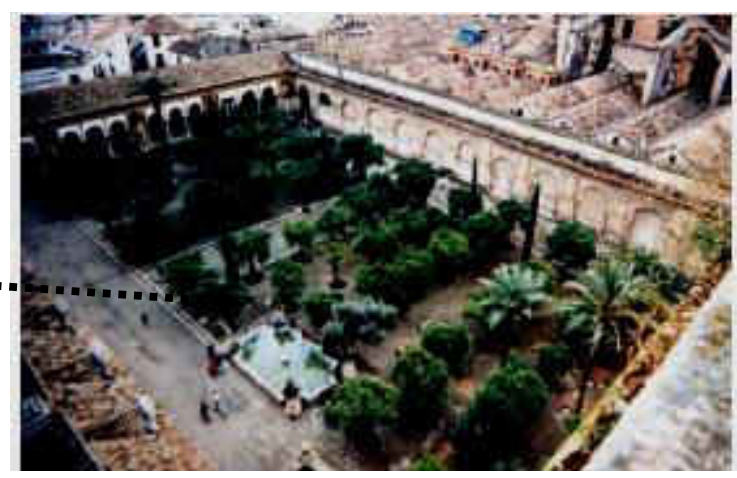

شكل (7) منظور خارجى لصحن البرتقال بالمسجد

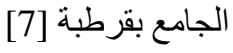

\section{المفاهيم المختلفة للحديقة العربية}

تتنوع الحديقة العربية قى أنماط وحدائق مختلفة ومتنو عة تشترك جميعها فى كثير من المفاهيم التى تميزهـا عن

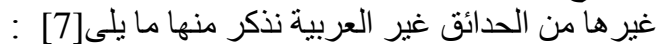
• يحترم تصميم الحديقة العربية المتطلبات الوظيفية لمئية لمجموعته المعمارية والظروف الطبوغرافية

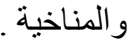
تنتاسب أبعاد الحدائق العربية مع نوع الفراغ اغوروظيفته وتصميمه.

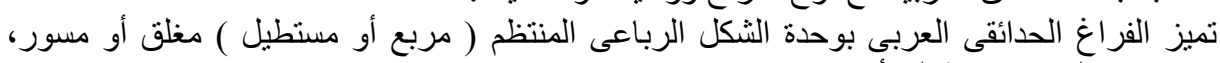

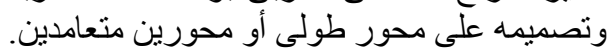

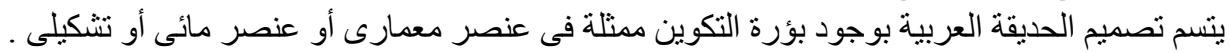

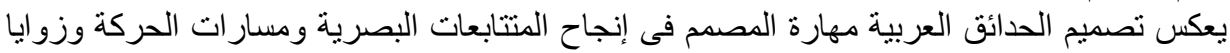

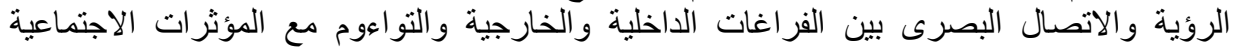

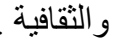

يوفر الفراغ الحدائقى العربى قدرا من الإظلال بمختلف وسائله كاستخدام التشجير الكثيف والممرات

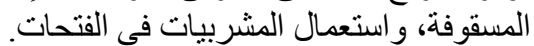

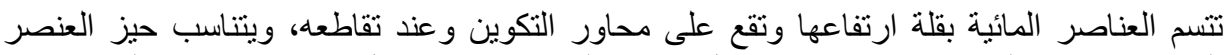

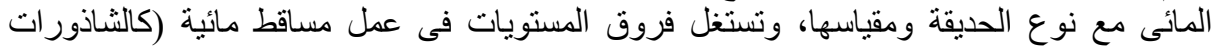

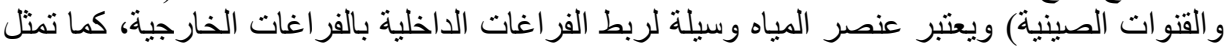
انعكاس للنص القرآنى " جنات تجرى من تحتها الأنهار ". 
تزرع الأفنية والحدائق العربية بكل ما هو مثمر أو مفيد "من فاكهة وثمار ونباتات عطرية وأثجار

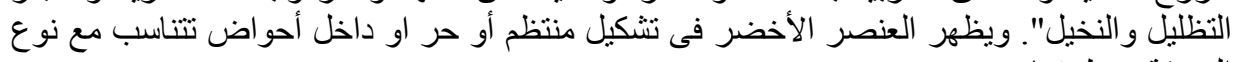
الحديقة ووظيفتها. تعكس الفنون العربية (الأشرطة المكتوبة والزخارف الهندسية والنباتية والزخارف المركبة ونادرا

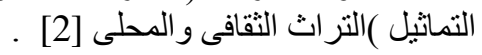

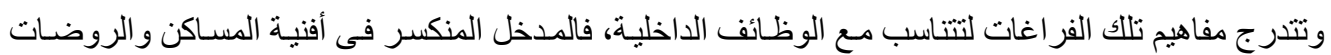

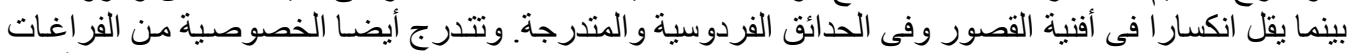

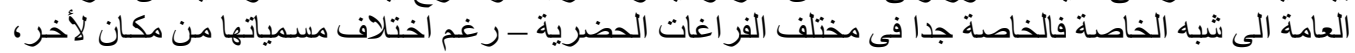

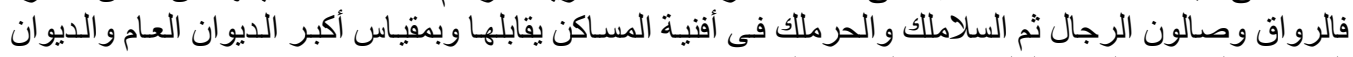

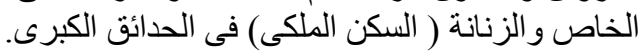

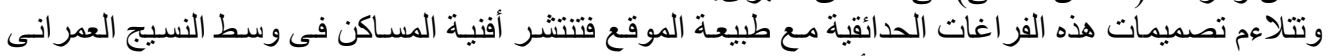

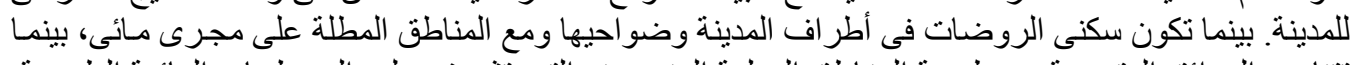

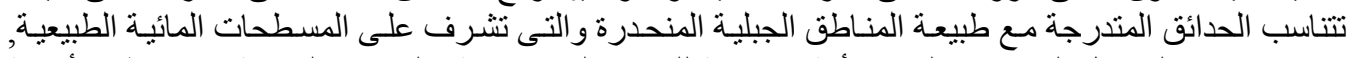

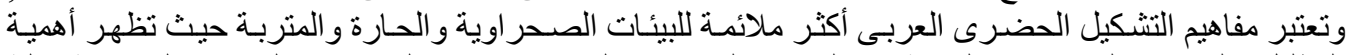

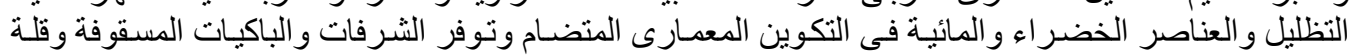

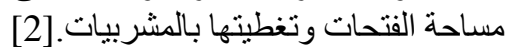

\section{3. المتطلبات العصرية للفراغات المفتوحة}

إن وجود خصـائص الحديقـة العربيـة التر اثيـة كفر اغ مفتوح مـن الفر اغـات الحضــرية المعاصـرة لـه مفهومـان.

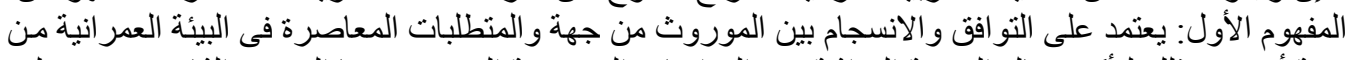

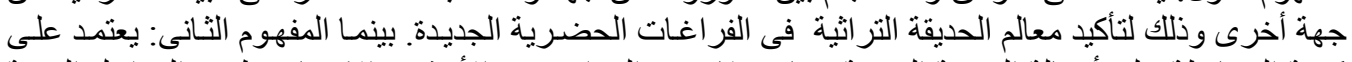

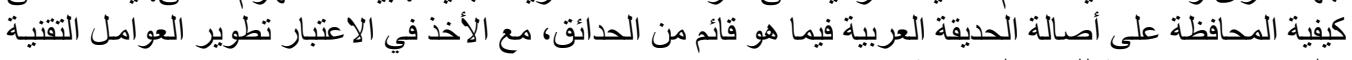
و النو احي الاجتماعية للحياة العصرية.

1-3 المتطلبات العصرية لنأنواع المختلفة من الفراغات المفتوحة

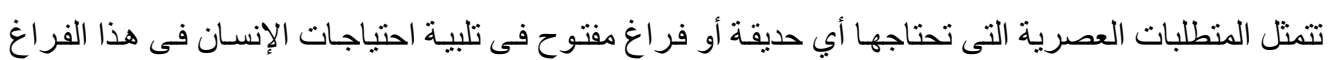

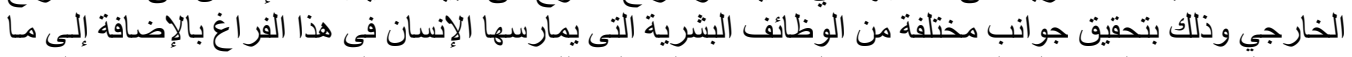

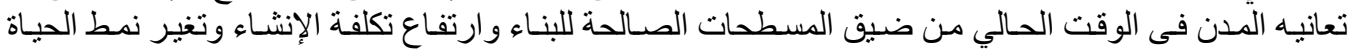

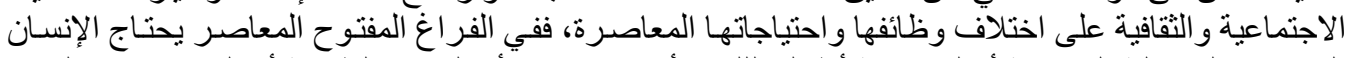

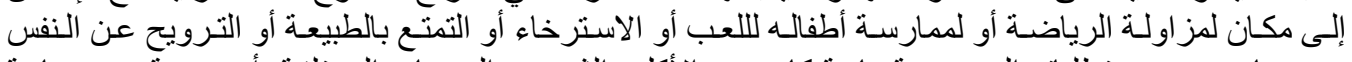

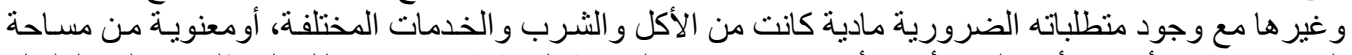

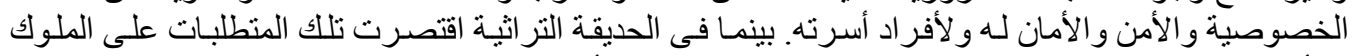

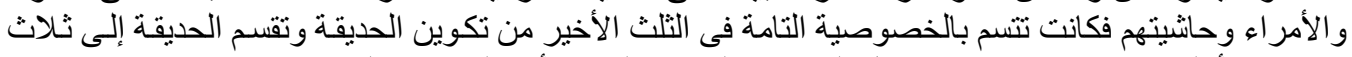

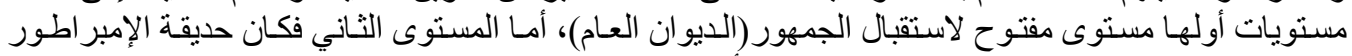

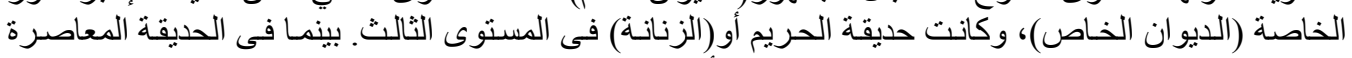

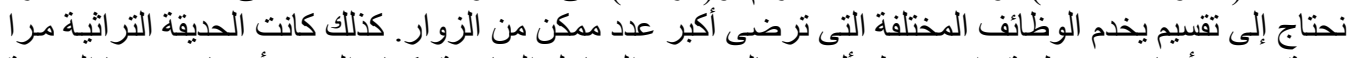

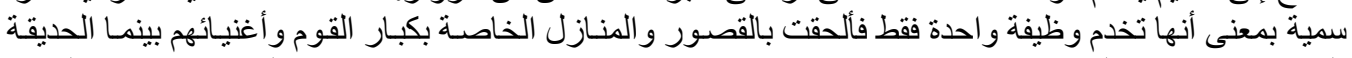

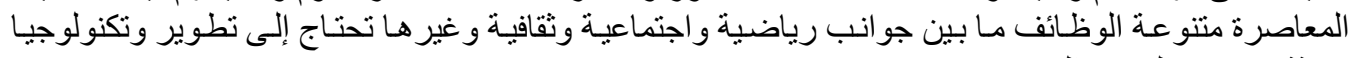
حديثة تنسم مع العصر الحديث.

\section{2-3 عوامل تصميم وتثكيل الفراغ المفتوح}

تتنوع المتطلبات و الاحتياجات لتصميم الفر اغات المفتوحة فى المدينة العربية من بلد لآخر ، حسب اختلاف البيئة

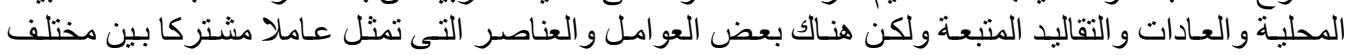
ثقافات الشعوب منها ما يلى [4] : 
الاختلاف الاجمالى للزوار: حيث ترتبط إمكانية تلبية احتياجاتهم وزيادة معدلات رضاهم بالتعداد

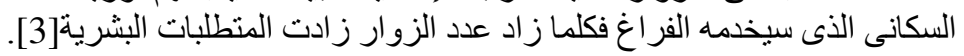

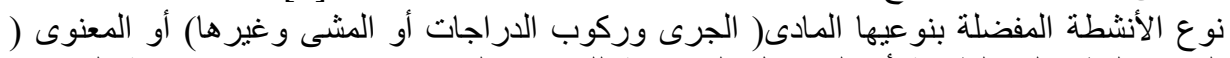

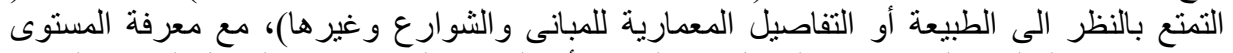

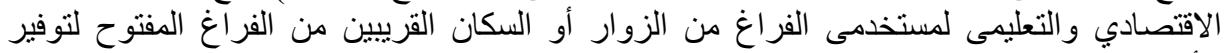

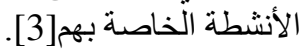

توزيع المناطق المفتوحة و الحدائق: وذلك بطريقة تكاملية تدريجية منسجمة ومتناغمة مع طبيعة المدينة و المستخدمين. التعامل مع الطبيعة: وذلك باستخدام المو اد المحلية و النباتات و الأشجار الطبيعية لتشكيل الحدائق لتصبح جزءء من الطبيعة. الحياة الاجتماعية: لا بد الطية عند تصميم الحدائق و الفر اغات المفتوحة أن تصبح أماكن اجتماعية للتعارف و الاحتكالك مع الطبيعة[4] ل

\section{3-3 3 دراسة تحليلية لفراغات مفتوحة معاصرة}

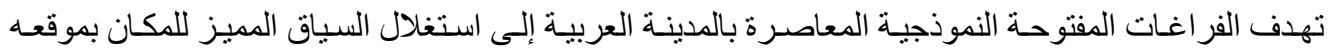

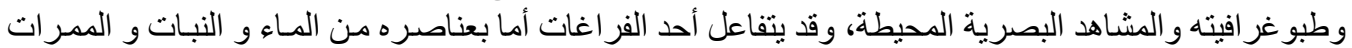

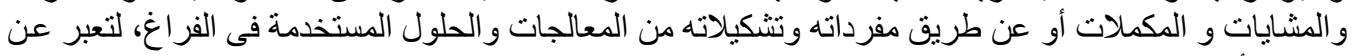

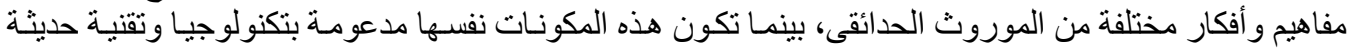

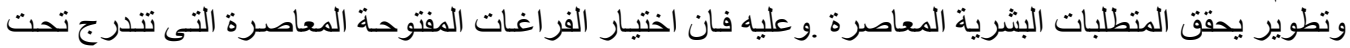

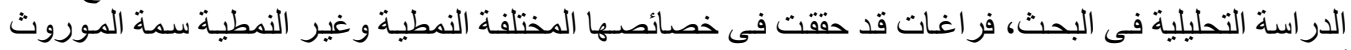

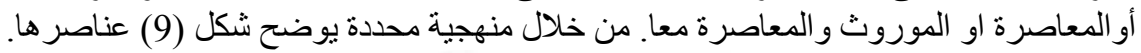

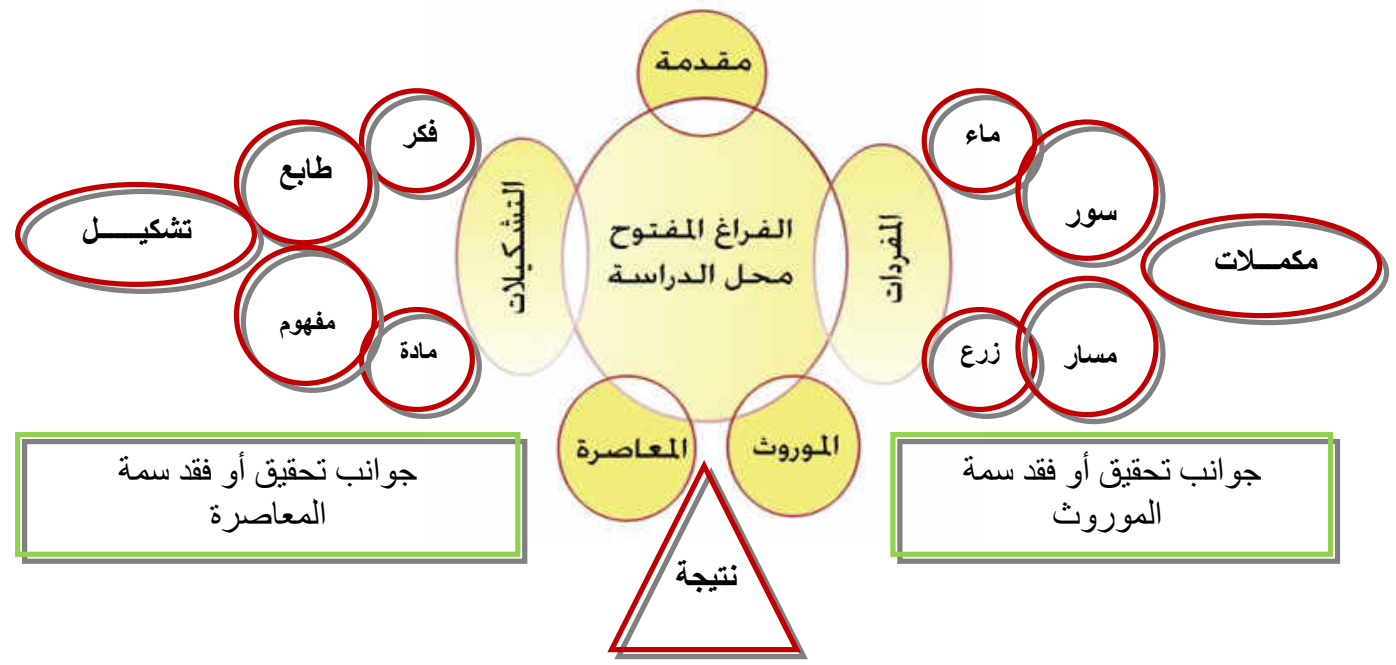

شكل (9) منهجية تحليل الفر اغ المفتو ح المعاصر 


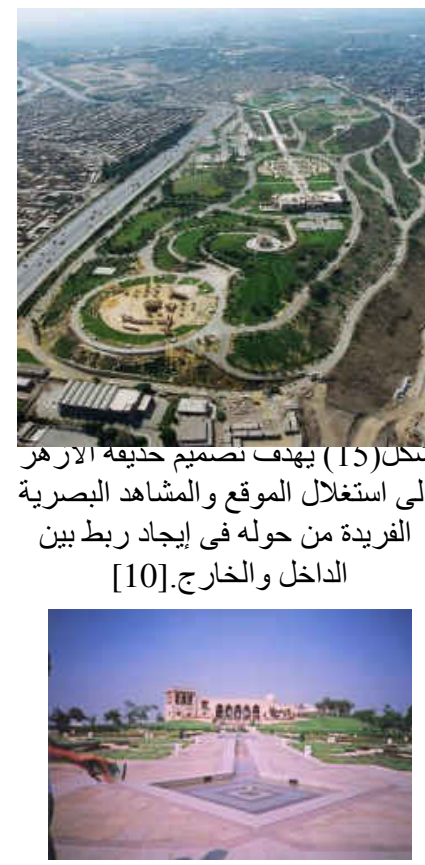

شكل(16) نأثرطابع حديقة الأزهر

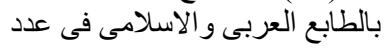
من المفردات و العناصر و التشكيل[9 فيع
1-3-3 حديقـــة الأزهـــــــــالقاهرة: تقع وسط المدينة على مساحة 71 فدان،

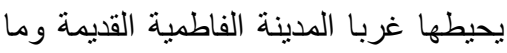
فيها من المساجد والأضرحة البارزة في الفئ

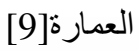

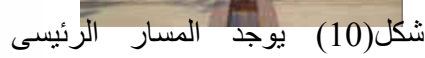

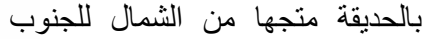

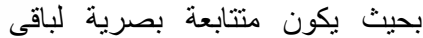
أجز اء الحديقة وماحولها.[10]

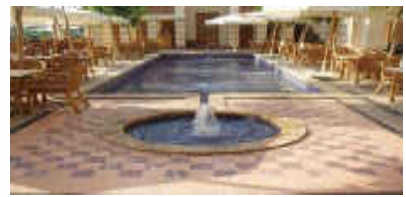

شكل(11) تنوع عناصر الماء بالحديقة

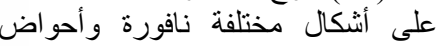
وبحيرة يجمع فيما بينها قنوات مياه. [9 نورة

شكل(17) استخدم المصمح المدخل الوظيفى

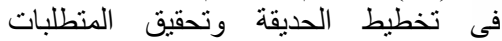

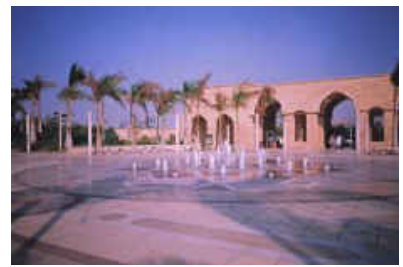

شكل(18) استخدمت مواد بناء طبيعية تخدم

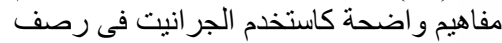
الأرضيات و النافور ات بالاق لكسر الجئ انعكاسات اشعة الثمس عليه. العصرية من الوظائف المختلفة .
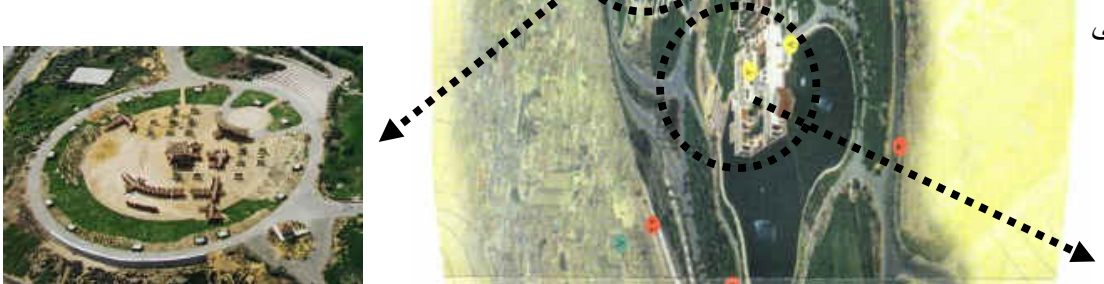

ف شي

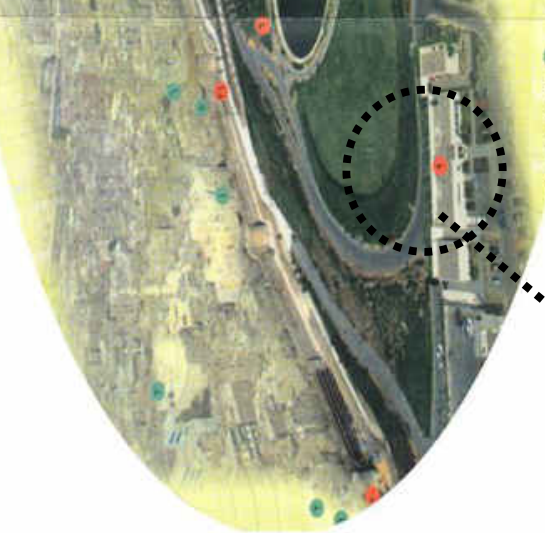

شكل(19) الموقع العام لحديقة الأزهر [10]

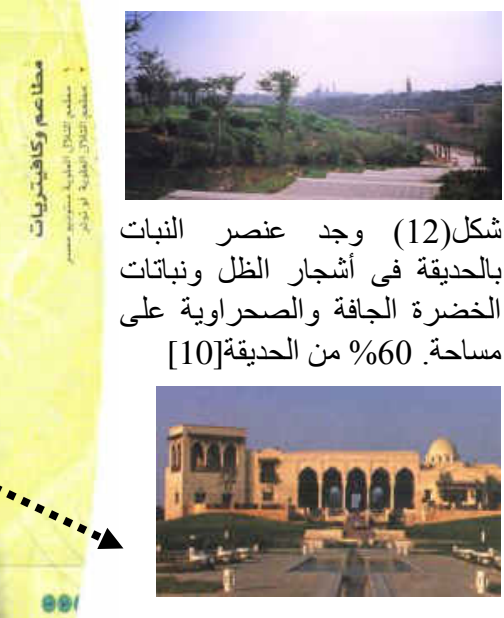

eer

شكل(13) احتوت الحديقة على الى

مبانى خدمية كالمطعم و الكافتيريا

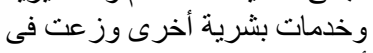

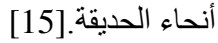

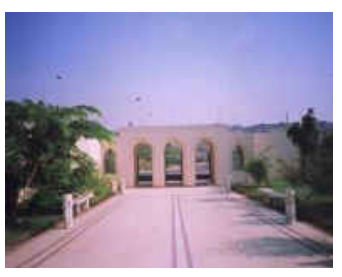

شكل(14-1) تمثل البوابات بناءا ضخما بالحديقة تميز باستخدام العقود العربية بناءاتية

والإسلامية.[15 بالميز 


\section{المعاصرة وحديقة الازهر :}

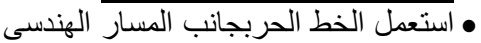

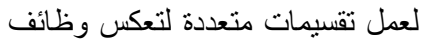

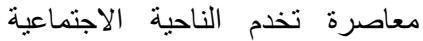

و الثقافية كأماكن لعبرة لعالب الأطفال

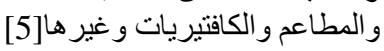

• • استخدمت مواد البناء الحديثة لمقاومة العابرة عوامل البرى والاحتكالك وظروف لمفنة البيئة المستحدثة [15 البرى

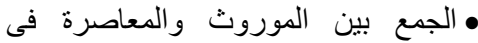

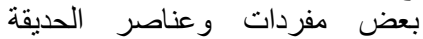

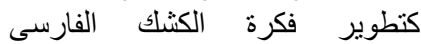

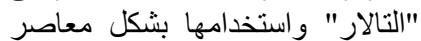

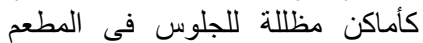
و الكافتتيريا بالحديقة.

\section{الموروث وحديقة الازهر :}

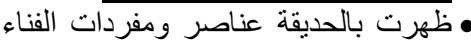

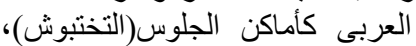

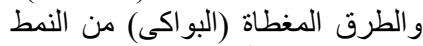

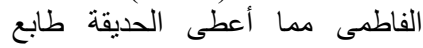

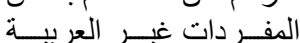

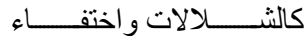

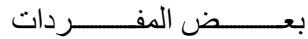

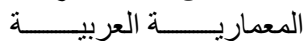
كـــالفنون النحتيـــــة الا أن

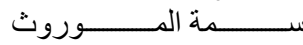

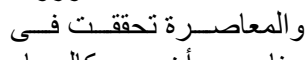

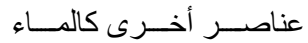

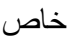

• تتعكس العناصر الفارسية والمغولية على الفى الفي تشكيلات العناصر المائية من النوافير المغولية

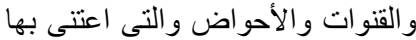

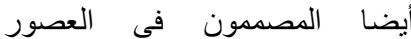

$$
\text { الاسلامية] [5] }
$$

• استخدمت الحديقة مفردات العمارة

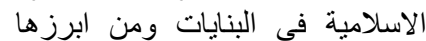

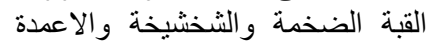
و الارتفاعات

و المشربيات الفيخدة

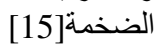




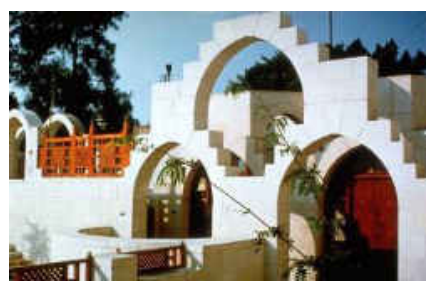

شكل(24) يهدف تصميم حديقة الطفل بالسيدة زينب الى تحقيق جانب الخصوصية مع تنوع الرئه

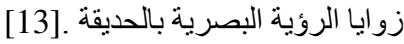

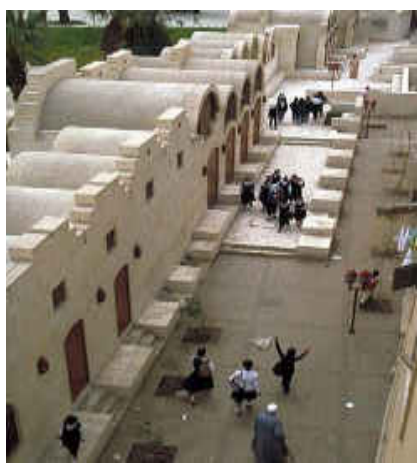

شكل(25) تأثر طابع الحديقة بالطابع العربى المحلى فى على عدد من المنائ المفردات

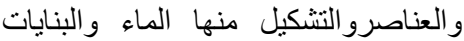

المعمارية و عناصر الحركة من السلالم

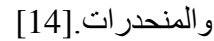

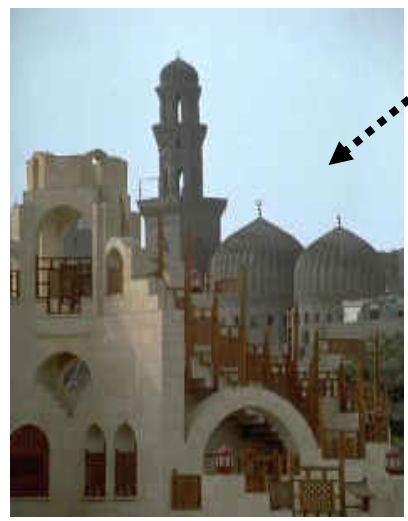

شكل(26) بحانب استخدام المدخل الوظيفى

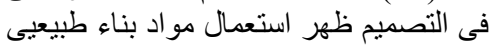

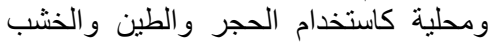
لانشاء العقود و القباب ونحوه [14

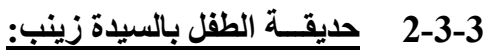
تعد ضمن منطقة تاريخية و أثرية تبلغ الخغ مساحتها

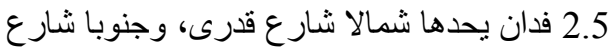
عبد المجيد اللبان، وشرقا مستشفى السيدة زينب وغربا شارع ابو الدهبـ[14]؛
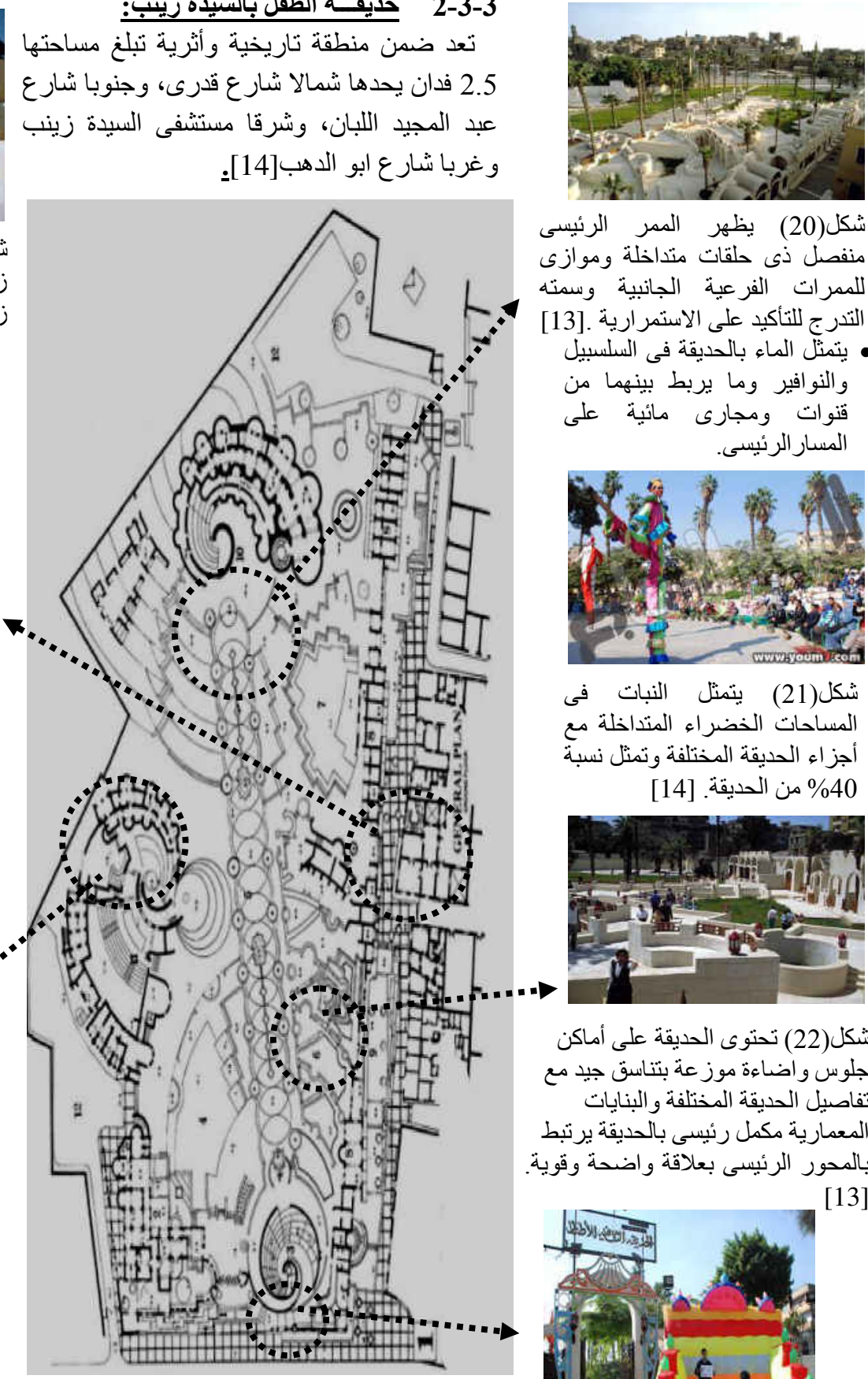

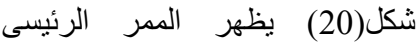

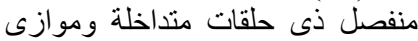

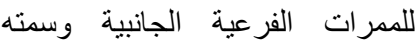

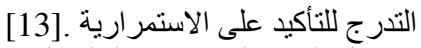

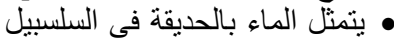

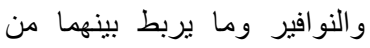

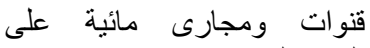

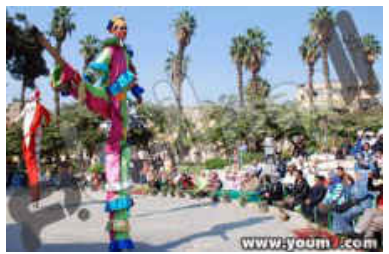

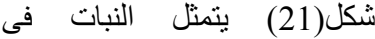
المساحات الخضراء المتداخلة مع في النمات أجز اء الحديقة المختلفة وتمثل نسبة المنة

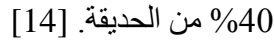

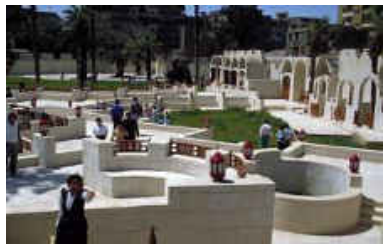

شكل(22) تحتوى الحديقة على أماكن

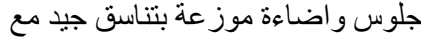
تفاصيل الحديقة المختلفة و البنايات المعمارية مكمل رئيسى بالحديقة يرتبط والبيات بالمحور الرئيسى بعلاقة واضحة بالئة وقوية.

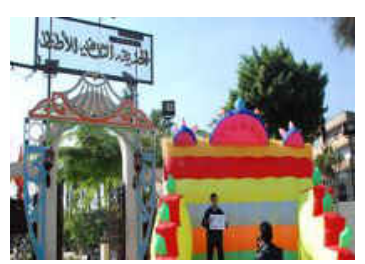

[13]

شكل(23) تظهر البوابات والاسوار بسيطة شكل(27) الموقع العام لحديقة الطفل

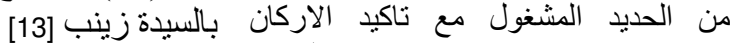

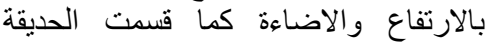

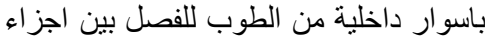

الحديقة المختلفة. [13 الطعة 
المعاصرة وحديقة الطفل بالسيدة زئب

• استعمل الخط الحر بجانب التشكيل

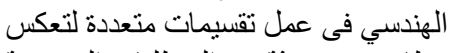

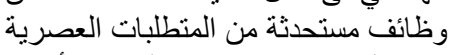
تخدم الناحية الاجتماعية و الثقافية كأماكن

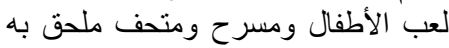

كافتيريا صغيرة و وكتبات و غير ها[14]

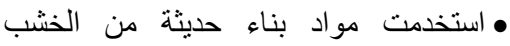

$$
\text { و الحجر و الرخام. }
$$

• تم الجمع بين الموروث و المعاصرة في بعض الرخ مفرد مفردات وعناصر الحديقة من السلسبيل و النو افير ومجرى المياه واستخدام النبات

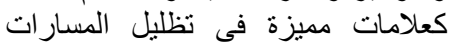
لتحقيق المتتابعة البصرية.

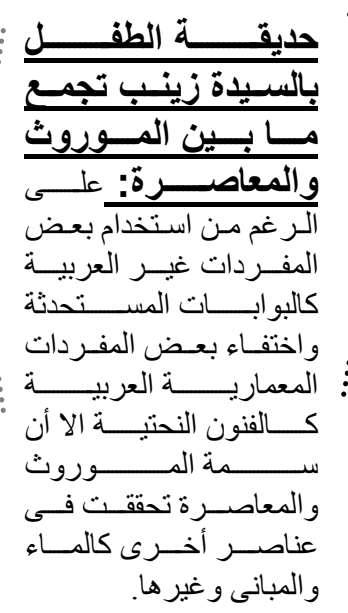

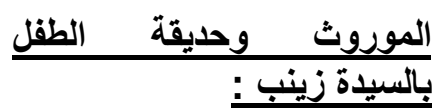

• يوضح التشكيل العام للحديقة الاحتفاظ ئزئ

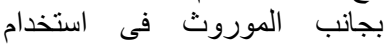
الاشكال الهندية الصريحة و الربط الهوريط

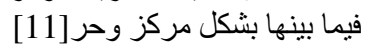
• تنعكس العناصر العربية على نشكيلات العناصر المائية من النوافير العربية العية

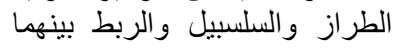
بمجرى مائى على طول المسلى ولرئل المسار

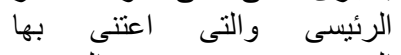

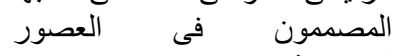
الاسلامية]

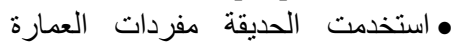

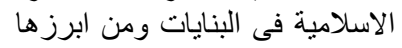

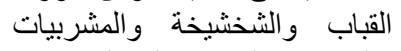
و المسار ات الهندسية المختلفة[14] 


\section{3-3-3 مديقة الاورمان بالجيزة: تواجه تمثال}

مصر للنهضة ويحيطها من الجنوب حديقة الحيو اند،

يهل تصميم الحديقة الى البساطة في التثكيل وخدمة جميع أجزاء الحديقة واعتبار عنصر النبات أهم أهم

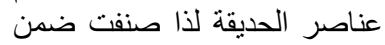
[9]. الحدائق النباتية

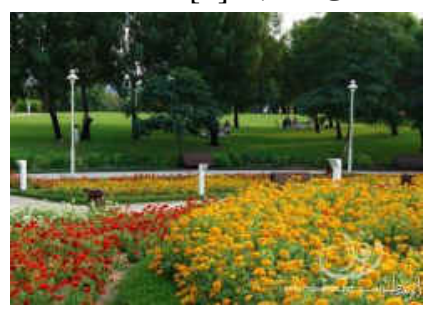

شكل(30) كان الطابع الرئيسى

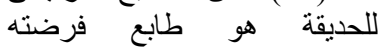

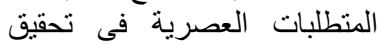
الوظائف المختلفة وبخاصة مشاتل النباتات.99] تاثر تصميم الحديقة باستيراد طابع

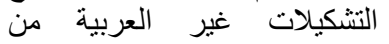
المفردات و والعناصر كالكبر الكبارى وعناصر الاضاءة المختلفة.[9]

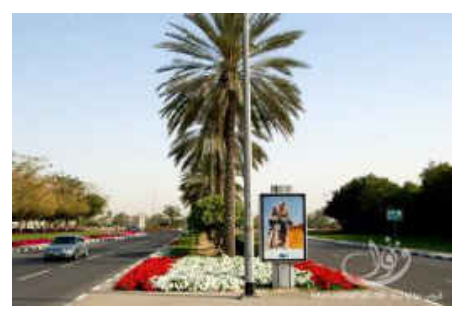

شكل(31) تم استخدام مو اد بناء

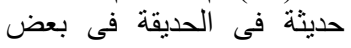
مفردات وعناصر الحديقة منها

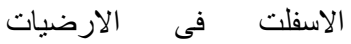
والرخام فى النافورات.] [9 الأى

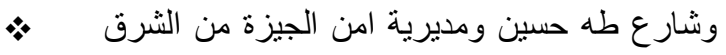

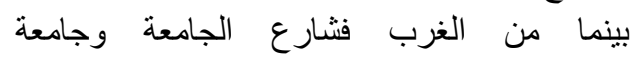
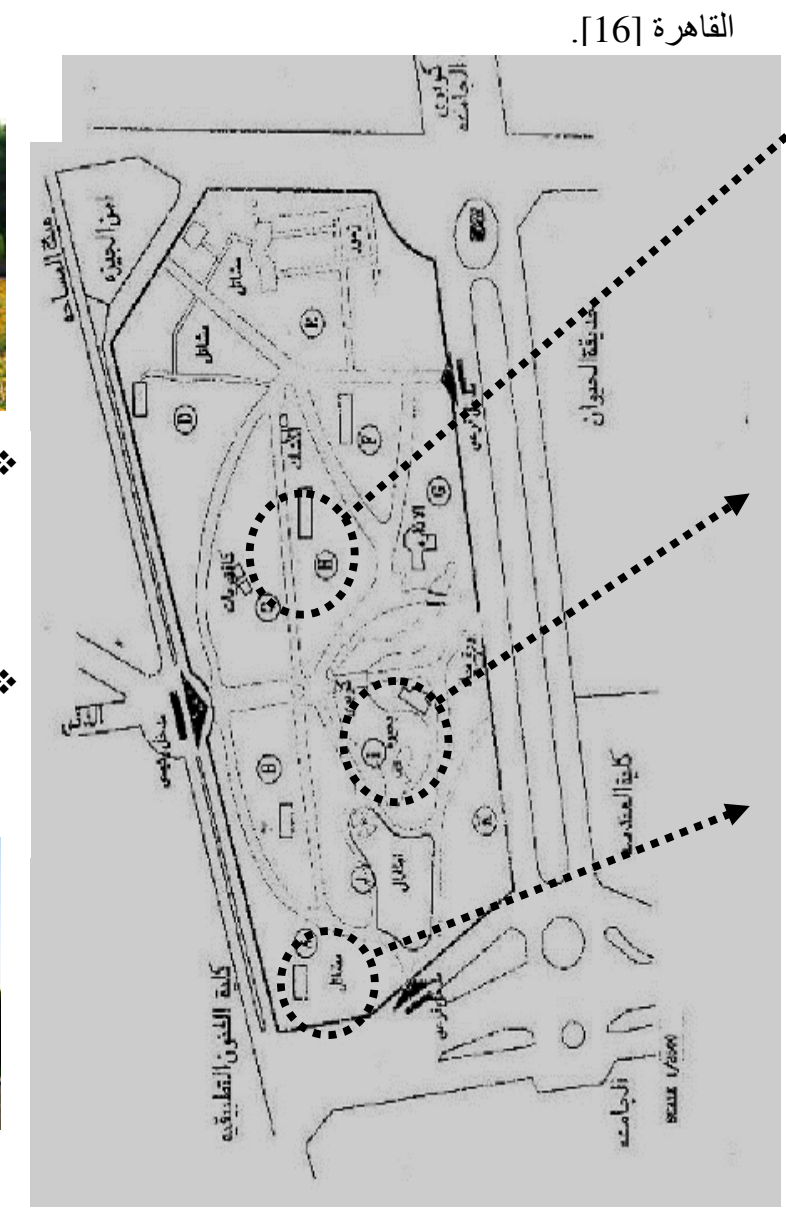

شكل(32) الموقع العام لحديقة الأورمان بالجيزة

[9]
• المسار الرئيسى بالحديقة

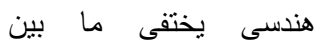
المسارات الفرعية والخئة مالخدمية الامامية والخلفية المتنو عة الفية

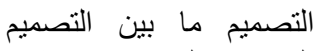
الهندسى و الحر.]9]

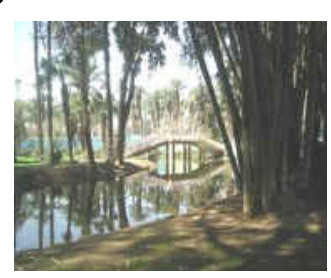

شكل (28) بتمثل عنصر الماء بالحديقة فى بحيرة صناعية ونافورة

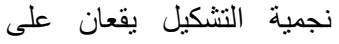
المسار الرئيسى للحديقة. [16]

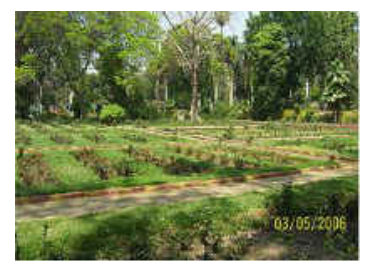

شكل(29) يعتبر النبات أهم عنصر فى الحديقة حيث يمثل 85 \% من الحديقة ويكون مشاتل من الانو من الانوبة النادرة و المختلفة.1171 من بانل

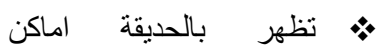
للجلوس و النو افير و عناصر الاضاءة والبنيات المعمارية موزعة جيدا على المسار ات الرئي الرئيسية و المختلفة. [9

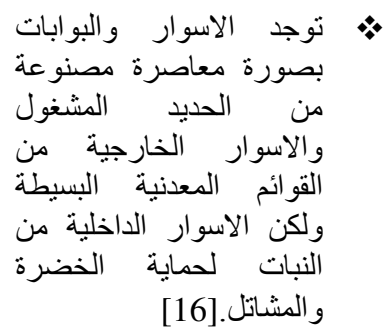




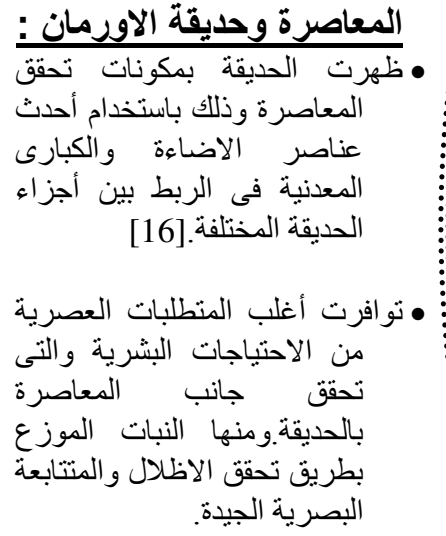

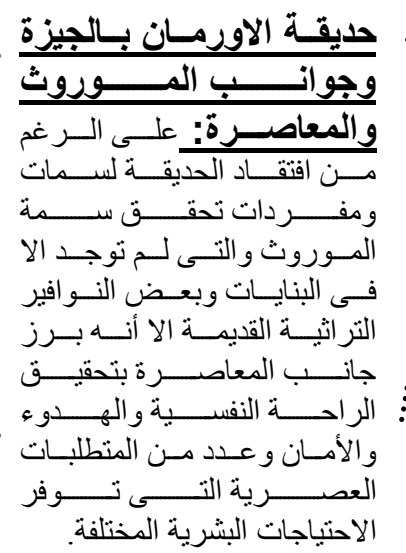

الموروث وحديقة الاورمان :

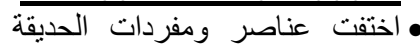
العربية بالحديقة لاسيما ان كان النان

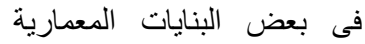
والنو افير التراثية القديمة.

• فقدت الحديقة جانب الموروث بكثير من العناصر و المفردات الغروبية

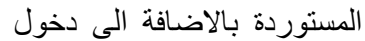

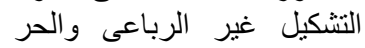
على التشكيل الهندسى المعروف بالحديقة العربية.

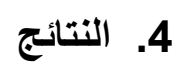

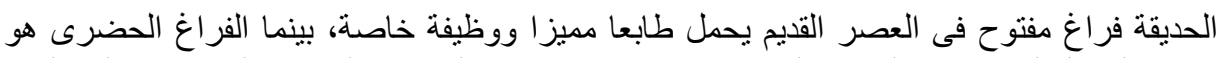
تطورا لفر اغ الحديقة فى العصر الحديث ذا طابع متتوع تبعا لوظائفه المتعددة النى تحقق المنطلبات

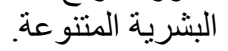
عكس تصميم الحديقة العربية خاصة فى العصور الاسلامية العديد من التفاعلات والاندماج الروحى

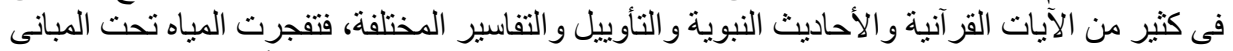

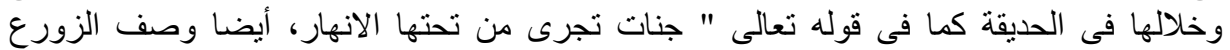

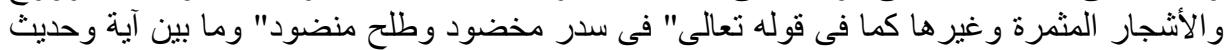
وتفسير وتآوييل وجدت الحيرة وايقة العربية.

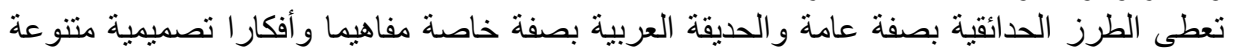

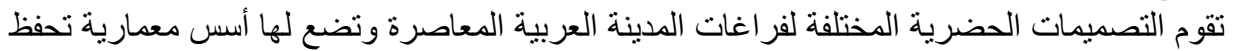

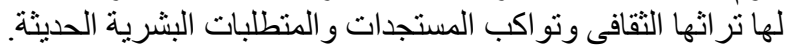

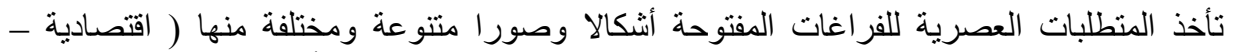

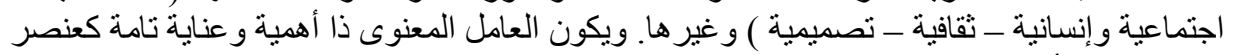

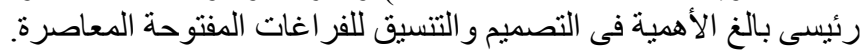

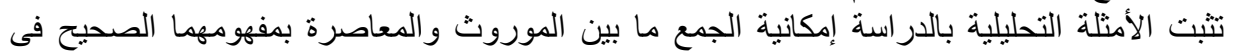

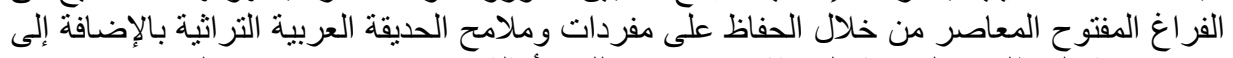

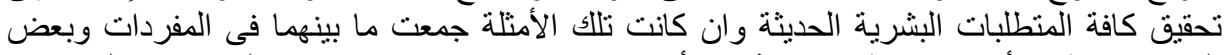

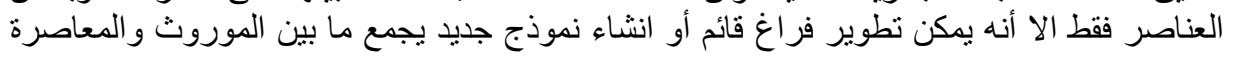
فى تصميم وتتسيق الحدائق والفر اغات المفتوحة.

\section{5.}

ليس المقصود من دراسة الحديقة العربية التمسك بحرفية الطراز العربي التاريخي وتفاصيله وبالتالي

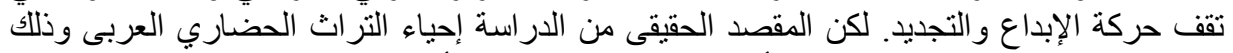

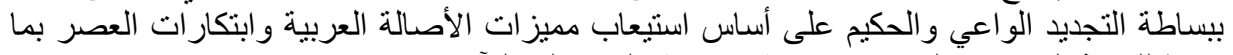
يحفظ للفراغ الحضري العربى شخصية واضحة وليس الئل تقليدا للآخرين.

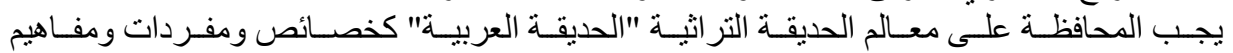

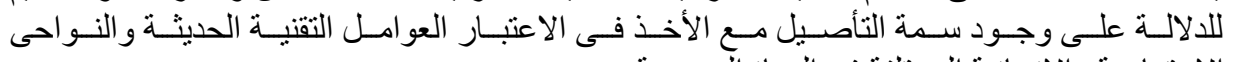
الاجتماعية والإنسانية المختلفة فى الحياة العصرية.

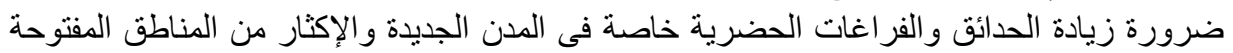

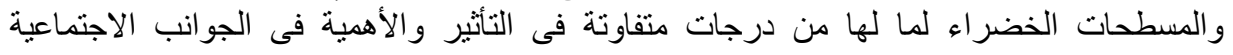


و الاقتصادية و البيئية و الجمالية وغير ها فى البيئة العمر انية وذلك من خلال نماذج الفر اغات المفتوحة

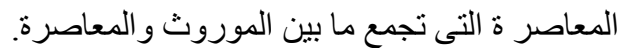

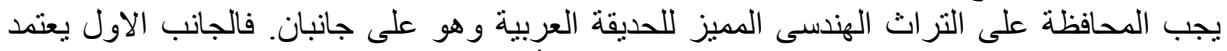

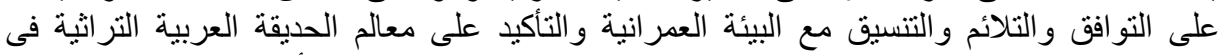

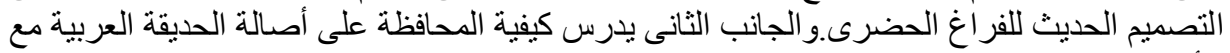

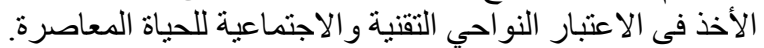

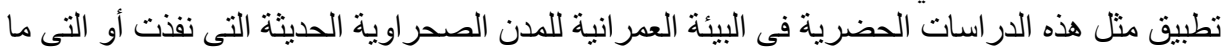

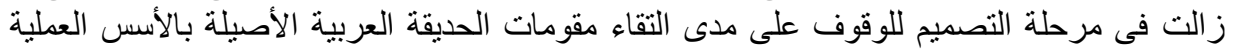

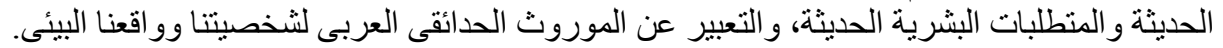

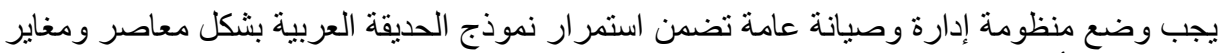
لما هى عليه ألان تتو افق حفظ الموروث إن مع تحقيق المتطلبات العصدرية.

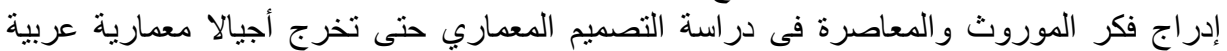

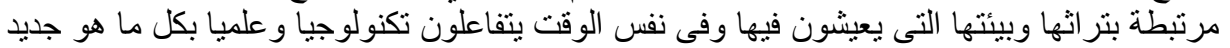
من العلم و التقدم في جميع المجالات.

\section{6. المراجع}

$$
\text { أولا : المراجع والأبحاث العربية }
$$

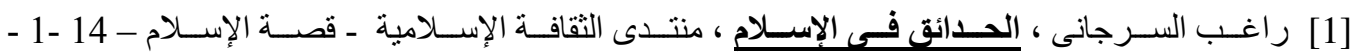

[2] مدوح على يوسف ، و وائل حسين يوسف، أنماط الأفنية والحدائق فى المدينة العربية ، ورقة بحثية، مجلة

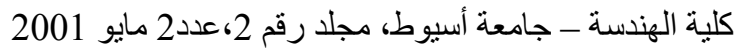

[3] أبو دهب محمود أبو دهب، طارق محمود ابو دهب، تصميم وتنسيق الحدائق، الدار العربية للنشر و التوزيع القاهرة طبعة أولى 1998

[4] أحمد محمد أحمد أمين توفيق عمليات تصميم المناطق المفتوحة الحضرية، رسالة ماجستير- كلية الهندسة -

$$
\text { جامعة القاهرة - } 1998
$$

[5] ريهام حمدي حسين عمر" تنسيق الموقع كوسيلة لإعطاء طابع مميز للفراغ الحضرى - العدائق العامة

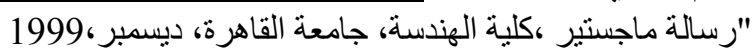

[6] مروى محمد عبد الباقى ،أسس تصميم المنتزهاتـ الحدائق العامة، رسالة ماجستير، كلية الهندسة - جامعة القاهرة.2003 مروم مبر

$$
\text { ثانيا : المراجع الاجنبية }
$$

[7] Aly Yousef Mamdouh El jardin en la arquitetura Musulmana Significados y Composicion, (tesis Doctoral), Escuela. T.S.de Arquitectura , Universidad Politecnica de Madrid, Espiana-1993

[8] Inji Mohei-Eldine "The design and conservation of Islamic gardens" Master, Eng Faculty, Cairo University - june 2008

[9]Frederick $R$, Steiner. 'The Living Landscape:An Ecological Approach to Landscape Planning'. Harry N. Abrahms. Mishawaka, IN, U.S.A 1993

[10]Aga Khan Trust For Culture, Project Briefal - $\underline{\text { Al Azher Park,Cand the }}$ revitalization of Darb Al-Ahmar- 2005 ثأثا : مواقع الانترنت

http:// Garden Visit. com - Date 12-12-2009 [11] 
www . Muslim Spain and European Culture.com - Date 12-12-2009 [12]

Date -15-1-2010 - http://www.iraqi-eng.net/vb/sendmessage.php [13]

2-3-2010 Date - - - - - حضارة الحدttp://www.m3mare.com [14]

2-7 -2010) (-http://www.youtube.com/watch El azher garden Date - [15]

[16] http://www.panoramio.com/photo/42397893-5-2010

[17] Google earth 